\title{
Probe into the leading work of young people's thought in the era of
}

\section{network new media}

\author{
Tian Liu $^{1}$ \\ ${ }^{1}$ School of Harbin University of Commerce, Harbin 150028, China \\ 40459422@qq.com
}

Key words: the new media era; youth thought; values; network; education

\begin{abstract}
: the current society has entered the information age, the new media represented by the Internet, as a strong thirst for knowledge, the majority of young people easy to accept new things are pursued, is gradually changing their way of learning, life, entertainment and even the way of thinking, modern youth ideological and moral is more and more obvious from the new the challenges of the media.In order to further do a good job of youth ideological work, so in the new situation to fully understand the new media represented by the Internet to the influence of contemporary youth, has a very important significance.

Today is a network of new media popular era, is the youth ideological cognition, law reform era, communication is flat, the popularization of the era, in today's society, plays an important role in the emergence of new media, new media network has penetrated into all aspects of life and youth to learn, work and youth. Is in the outlook on life and values formation period and the period of establishment, the external culture is easy to have a great impact on its new media rich leading ideological work, increase the difficulty of the work of leading thought and requirements, because of its unknown, virtual.Therefore, to do the work of young minds to lead, must be brought to the new media of the beneficial and adverse effects, based on in-depth investigation of the use of new media on youth, but also actively explore effective ways to carry out ideological work by leading new media.The combination of new media technology and Youth Ideological and political education is imperative, and the new media has spread easily, spread carrier, the main body of the "fragmentation" phenomenon, which gives the combination of many obstacles.Social need to integrate the objective information point of view, the growth of service resources, the latest media platform, to strengthen the ideological guidance of young people to provide new media support and at the same time the community needs to guide the youth to use the new media technology correctly, develop good media literacy, the youth training to become a speculative type, innovative talents.
\end{abstract}

First,Education means "revolution" in the new media

In today's society, the network technology is increasingly developed, it has been an important part of the ideological and political work. Therefore, the combination of Ideological and political education and the new media is imperative.But to realize the trend of "fragmentation", adhere to the guiding ideology of the socialist core values, to consolidate and expand the public opinion, help students to extract useful information from the network information ocean, the wave of the rapid integration of social solidarity, the realization of "China dream", it is necessary to understand the main ideas in the work, grasp the basic aspects.

New media sources of information more diverse, more and more information is updated faster and faster, the information is more extensive, more diverse information involved in the feedback, 
the channels of dissemination of information is more abundant.With the development of science and technology and the improvement of the level of consumption, people have a better understanding of science and technology, the intelligent mobile phone, tablet computer and other new media technology carrier rapid popularization, new media technology has been developing rapidly. New media such as Internet application platform has become the obtain employment information, for young college students learning exchanges, the most as an important tool for shopping and entertainment.Therefore, in the process of strengthening the ideological and political education, new means of education in the new media, strengthen and play the position, is an important aspect of the current educational work can not be ignored.

Now, the popularization of the Internet, make public discourse unprecedented liberation, the Internet is flooded with all kinds of information in the form of a lot of new ideas, new concepts emerge in an endless stream ideology, increasingly fierce, thinking mode and value orientation of diversified increasingly significant, the infiltration of Western world ideology is further exacerbated by the mainstream values is a serious challenge .Young people active thinking, innovative consciousness, willing to accept new things, but "life values, values, the world outlook" is still in the process of formation, subjective awareness is vulnerable to external environmental impact and interference.Therefore, under the new situation, how to accurately grasp the development of new media, to effectively seize the ideological lead heights of college students, to become an important work of Ideological and political education in Colleges and universities.To this end, we must use the Internet thinking, and constantly optimize the user experience, big data mining youth needs, relying on the new media to effectively lead the youth in the realization of the Chinese dream in the process of training.To the youth, to optimize the user experience of new media; with youth oriented, to win the youth with differentiated services; to friends with education transfer values, with big data read youth training of young opinion leaders, the formation of three-dimensional online and offline interaction.

Second, the construction of network culture in the new media

Because of the network with the growth of young people, so the ideological and political workers should take the initiative to strengthen the study of the cultural construction of network law, found that combination in accordance with the education laws and rules of the network, found that both balance and safety education, truly the network construction, the development of good, good use, to further strengthen the construction of network platform.To build a good network education platform, we must continue to increase the affinity, attraction and cohesion, and constantly increase the number of hits and visits, building a high quality of network culture.

The network is not only a tool, but also an environment. To convert the language environment, change the way of expression, follow the network language habits and expression of educational philosophy with the vivid story, with the popular language and way of clarifying the truth.In order to give full play to the positive energy of the network, we must carry on the ideological and political education work using the social network construction, organization and implementation of network information system, to seize the focus of the young, hot and difficult, in response to the problem of.

Because of the rapid development of new media, the news of the massive growth and spread, the value orientation of the increasingly diverse and conflict with the hot social network, information technology, fast food, fragmentation, eyeball, entertainment, also leading the challenge to the young thought.Because young people's thinking is active, information flow, emotional rich, especially the popularity of the network, so that the content can be the first time the youth are perceived and cause their attention.However, a series of unfavorable factors that make a lot of 
young people do not have the history, the system, a comprehensive look at the problem, to lead the work of young people's thinking has brought challenges.To win the young people's trust in the complex and diverse value communication, strengthen the youth's faith and lead the youth development, it is necessary to strengthen the pertinence and timeliness of the youth thought.Through the theory and practice, it is the key to build a network culture platform, expand the youth practical education carrier, and strengthen the youth self education.

Third, values are loaded into the new media

Do a good job in the core values of education, the key to grasp the three dimensions.First of all, to grasp the mechanism dimension. The key measure of core values education is to build a long-term mechanism.Core values education is not a surprise movement, but a long-term project, with a systematic and complex.Central and the Ministry of education, the work of the deployment of the design of the establishment of long-term mechanism to improve the management measures, penetration into the whole process of educating people put forward clear requirements. To ensure the long-term education of core values continued effectively and achieve the desired effect of education, we must do the top-level design and institutional arrangements, and gradually form a resource, system security, supervision inspection, evaluation of the effectiveness of a long-term mechanism.Secondly, to grasp the dimensions to grasp.Core values education should run through the process of the development of young people, rooted in the concept and behavior of youth.If we want to embody the core values of education and management services at all levels, we must combine the new media and teaching methods, and constantly improve the educational system and mechanism.Also the core values of the content and requirements embodied in the curriculum reform and teaching system reform and innovation, so that the core values of socialism has become a teacher can speak good, students can learn the key content.The students want to further understand the situation, social situation, the people, understand correctly understanding the relationship between the future and destiny of the country and their own growth and development, to further strengthen the study hard, grow up to serve the ideals and beliefs, to guide students to actively participate in social investigation, volunteer service, public service activities of social practice.In order to actively expand the core values of the spread of education, we should actively carry out the spread of campus culture, the creation of campus literary works, research and development of campus cultural products and other activities.Finally, the innovation dimension to grasp.The information in this multi communication era, we must innovate the ideas and methods, characteristics and changes, research object of education teaching, individualized strategy, strengthen the guidance to students' independence, selectivity, diversity is more and more obvious, the formation of thought is easily affected by the environment, experience, influence of trend and other challenges.

Example demonstration in the core values of education can not be missing.The deeds of these models should make the students feel noble, respectable, credible, and can be learned.The sacred and solemn ceremony of the ceremony has a strong spiritual power.We want to make the important ceremony carrying core values and the mission of education, should pay attention to the use of the opening ceremony, graduation ceremony, Youth Day, national day, traditional festivals such as the key time node, carefully set up to carry out the theme of education, to strengthen the sense of ceremony.And also strengthen the code of conduct.We should give full play to the guiding role of system constraints and norms, by adhering to the correct policy guidance, improve the student code, code of conduct convention, study and formulate guide students thinking and behavior "positive list" and "negative thoughts and behavior constraint error list", to encourage compliance with the core values of the behavior, which violates the core values phenomenon. To enable students to 
strictly abide by the norms of behavior, consciously cultivate good behavior habits of thought.

Fourth, the theoretical guidance of the new media

At present, adhere to lead on Youth Ideological and political work, to clarify the fallacy in the network right from wrong, innovative tools, promote the propagation force, guiding force, influence, credibility in the young people.Do a good job of youth thought to lead the work, always put the right political direction in the first,adhere to the principle of Party spirit,enhance the par consciousness, and , in the ideological and political action is always highly consistent with the central committee.To guide the majority of young people continue to enhance the "three confidence", and firmly listen to the party, with the party to go;Will be "around the center, the overall situation of the service",Help the majority of young people to deeply understand the new ideas and Strategies of the Party Central Committee of the CPC Central Committee and the general secretary Jinping Xi .The party's theory and policy into conscious action of youth, give full play to the role of force in the process of building a well-off society;To "unite the people and boost morale", Follow up the unity and stability, positive propaganda, persevere to deepen the socialist education Chinese dream and Chinese characteristics, grasp the guiding ideology, degree, efficiency, guide the youth to see more mainstream, look at nature, look at the bright side, firmly establish the five development ideas, strengthen the development of confidence; Vigorously carry out the socialist core values cultivation and practice, the positive orientation of legislation, the rooted social core values and positive; In the face of erroneous ideas to flag sword, firmly struggle with the wrong words, guide the youth striving to be a good Netizen, a good voice, spread positive energy;Guide Chinese youth to expand international perspective, establish a vision of the world, to learn all the outstanding achievements of civilization, for Overseas Youth China tell a good story, to show China youth style, to speak to the spirit of reform and innovation to promote the comprehensive guidance.

No matter how the development of the times, youth as an advanced society, the thought of leading the work will be the focus of social concern. We should follow the logic of history, theory of logic, practice logic, system, comprehensive, objective and rational to look at the new network media, to play its positive role.Unity of thought and action, human resources can be brilliant achievements.Therefore, strengthening youth ideological work leading political awareness, overall awareness, awareness of the core, with consciousness, let young students to a higher, farther, more healthy direction, we will be able to create a new situation of propaganda and ideological work, gather up a strong power of youth to achieve Chinese dream.

\section{Reference:}

[1] To strengthen the ideological morality education lead to enhance the quality of Ideological and political education of college students --- Gang,Feng <Ideological Education Research >-2015-03-25

[2] Zhixian Pan , Lihong Li , National College Students' network civilization promotion association, the League will be held [N]--- China Youth Daily 2016-05-16, 03 Edition

[3] Jiquan Wang ,Bo Yuan , Jinping Xi on the Internet [N]--- people.com.cn - People's Daily Overseas Edition, 2015-12-16

[4] Wanjiao Zhou, the Central Committee of China Netcom Group held a network of young people to build China dream, the theme of the forum [N]--- China Youth Daily, 2016-05-06,03 version

[5] Xiangyang Xin, China Road and China Youth Development [N]--- China Youth Daily, 
2016-05-26,02 Edition

[6] National College Students Network Culture Promotion Association, and network, youth play [N]--- China Youth Daily, 2016-05-16,03 